\title{
An investigation into the variation of nutritional status of university students in relation to the level of study
}

\author{
L. Wing, I. Alauntye and F. Amirabdollahian \\ School of Health Sciences, Liverpool Hope University, Liverpool, L16 9JD
}

The association of stress and poor dietary habits have been previously reported among individuals who have experienced the transition to college and university ${ }^{(1)}$. Despite previous studies focusing on the weight gain of university students during the first year of study ${ }^{(2)}$; there is limited research with regards to the nutritional status of undergraduate students during the progression in the $1^{\text {st }}, 2^{\text {nd }}$ and $3^{\text {rd }}$ year of study. The purpose of this study was to investigate the variation of nutritional status of undergraduate university students in relation to the level of study.

Following obtaining ethical approval, participants were recruited from the $1^{\text {st }}, 2^{\text {nd }}$ and $3^{\text {rd }}$ year of study at universities in North West of UK $(\mathrm{N}=238)$. The assessment of nutritional status included anthropometrical and physical measures such as height, weight, waist and hip circumferences, body composition and blood pressure as well as biomarkers of fasting capillary blood lipid profile. A validated three day food and physical activity diary was used to assess the typical nutrient intake of the participants. The dietary data was analysed using dietary assessment software Microdiet and statistical analysis was conducted using software SPSS version 22.0. Inferential statistics included the analysis of the variance to discover if there was any significant variation in nutritional status in relation to the level of study. The statistical significance was set at $0 \cdot 05$.

Despite detailed analysis of anthropometric, dietary and laboratory measures of the nutritional status, there were very few significant variation associated with the level of study. The only significant differences are shown in table 1.

Table 1: The detail of nutritional status for $1^{\text {st }}$ year $(\mathrm{N}=51), 2^{\text {nd }}$ year $(\mathrm{N}=54)$ and $3^{\text {rd }}$ year $(\mathrm{N}=127)$ undergraduate university students. In columns, means that have no superscript in common are significantly different from each other $(\mathrm{P}<0.05)$.

\begin{tabular}{|c|c|c|c|c|c|c|c|}
\hline & \multirow[b]{2}{*}{ Year of study } & \multicolumn{3}{|l|}{ Males } & \multicolumn{3}{|l|}{ Females } \\
\hline & & $\overline{\text { Mean }}$ & SD & $\bar{N}$ & Mean & SD & $\mathrm{N}$ \\
\hline \multirow[t]{3}{*}{ Waist to Hip Ratio } & 1 & $0 \cdot 81^{\mathrm{a}}$ & $0 \cdot 08$ & 23 & $0.77^{\mathrm{a}}$ & 0.08 & 28 \\
\hline & 2 & $0.87^{\mathrm{b}}$ & 0.06 & 24 & $0.75^{a}$ & 0.06 & 30 \\
\hline & 3 & $0.83^{a}$ & $0 \cdot 06$ & 54 & $0.77^{\mathrm{a}}$ & $0 \cdot 06$ & 73 \\
\hline Whole blood total HDL & 1 & $1 \cdot 15^{\mathrm{a}}$ & $0 \cdot 31$ & 23 & $1.45^{\mathrm{a}}$ & $0 \cdot 33$ & 28 \\
\hline \multirow[t]{2}{*}{$(\mathrm{mmol} / \mathrm{L})$} & 2 & $1 \cdot 34^{\mathrm{a}, \mathrm{b}}$ & $0 \cdot 33$ & 24 & $1.42^{\mathrm{a}}$ & 0.45 & 30 \\
\hline & 3 & $1 \cdot 36^{\mathrm{b}}$ & $0 \cdot 29$ & 54 & $1.38^{\mathrm{a}}$ & $0 \cdot 35$ & 73 \\
\hline Percentage Contribution of & 1 & $47 \cdot 2^{\mathrm{a}}$ & $9 \cdot 2$ & 23 & $43.4^{\mathrm{a}}$ & $7 \cdot 6$ & 28 \\
\hline Carbohydrate into energy & 2 & $42 \cdot 2^{\mathrm{a}, \mathrm{b}}$ & $10 \cdot 9$ & 24 & $44.7^{\mathrm{a}}$ & $7 \cdot 7$ & 30 \\
\hline intake $(\%)$ & 3 & $41 \cdot 3^{b}$ & 8.9 & 54 & $47 \cdot 4^{\mathrm{a}}$ & $8 \cdot 9$ & 73 \\
\hline Average daily energy & 1 & $3412^{\mathrm{a}}$ & 1144 & 23 & $2568^{a}$ & 495 & 28 \\
\hline expenditure (kcal/day) & 2 & $3646^{\mathrm{a}}$ & 910 & 24 & $3026^{\mathrm{b}}$ & 927 & 30 \\
\hline estimated from PA diary & 3 & $3487^{\mathrm{a}}$ & 1011 & 54 & $2686^{\mathrm{a}, \mathrm{b}}$ & 683 & 73 \\
\hline
\end{tabular}

In conclusion, no variation was seen in energy and macronutrient intake, anthropometric measures, blood pressure and/or majority of the biomarkers of glucose and fasting capillary blood lipid profile based on the years of study. This is in contrast with the popular notion of the 'Freshman 15' suggesting exacerbating nutritional status and dietary habits in the first year of the study at higher education $^{(3)}$.

1. Anderson A.D., Shapiro R.J. \& Lundgren D.J. (2003) Eating Behaviours, 4, 363-367.

2. Serlachius A., Hamer M. \& Wardle J. (2007) Physiology \& Behaviour, 92, 548-553.

3. Vella-Zarb A.R. \& Elgar J.F. (2009) Journal of American Health, 2, 161-166. 